\title{
Expectation of fairness: a turning point in the professional satisfaction of Iranian nurses
}

\author{
Forough Rafii ${ }^{1}$, Alireza Nikbakht Nasrabadi ${ }^{2}$, Zahra Sadat Dibaji Forooshani ${ }^{3}$
}

${ }^{1}$ Ph.D. of Nursing, Professor, Nursing Care Research Center, Faculty of Nursing and Midwifery, Iran University of Medical Sciences, Tehran, Iran

${ }^{2}$ Ph.D. of Nursing, Professor, Department of Nursing, School of Nursing and Midwifery, Tehran University of Medical Sciences, Tehran, Iran

${ }^{3}$ Ph.D. Candidate of Nursing, Department of Nursing, School of Nursing and Midwifery, Tehran University of Medical Sciences, International Campus (TUMS-IC), Tehran, Iran

\section{Type of article: Original}

\begin{abstract}
Introduction: The professional satisfaction of staff is one of the most challenging organizational concepts that can enhance the efficiency level of organizations. In a similar vein, the professional satisfaction of nurses is of considerable importance, in that, professional dissatisfaction among nurses could result in emotional detachment, depression, anger, evasion from work, and inefficacy and would negatively impact the organization's work rate. The aim of this study was to understand Iranian nurses' experiences of the concept of professional satisfaction.

Methods: This was a qualitative study conducted with a targeted sampling of 10 nurses ( 4 men and 6 women) in 2015. The data were collected through conducting in-depth interviews, and textual data were analyzed subsequently using the Qualitative Content Analysis (QCA) method.

Results: The findings of this study pointed to "fair conduct," which was comprised of three sub-categories, i.e., expectation of fairness in social-professional settings, expectation of fairness in receiving professional benefits, and expectation of fairness in the area of professional interactions.

Conclusions: There are various ups and downs in nursing due to the challenging nature of the profession, from the initial education at the university until retirement. According to the findings of this study, a lack of fairness in social-professional settings, a lack of fairness in receiving professional benefits, and a lack of fairness in the area of professional interactions were among the factors that have great impacts on the degree of professional dissatisfaction among nurses.
\end{abstract}

Keywords: expectation of fairness, professional satisfaction, nurses, Iran

\section{Introduction}

\subsection{Background}

Today's world is a world of organizations, and their main operators are the people who invigorate them and prepare the grounds for the realization of their objectives. Without people, the concepts of organization and management would become meaningless (1). Therefore, professional satisfaction on the part of manpower is one of the most important factors in the efficacy of organizations. The issue of professional satisfaction has been studied repeatedly with respect to various organizations since the $1920 \mathrm{~s}$, and, according to many experts, it is one of the most challenging organizational concepts and the basis behind the many management policies adopted to improve organizational effectiveness (2). Health care organizations and treatment centers are responsible for maintaining the health of all citizens in a society, and nurses have a key role. Their success in fulfilling this role depends on the measures taken by competent managers who recognize the prominent factors involved in the activities of nurses and seek to create favorable work conditions in order to enhance their professional satisfaction (1). Previous studies have

\section{Corresponding author:}

Zahra Sadat Dibaji Forooshani, Department of Nursing, School of Nursing and Midwifery, Tehran University of Medical Sciences, International Campus (TUMS-IC), Tehran, Iran.

Tel: +98.9123878997, Email: atousadiba@yahoo.com

Received: December 07, 2015, Accepted: January 28, 2016, Published: June 2016

iThenticate screening: January 27, 2016, English editing: March 12, 2016, Quality control: May 06, 2016

(C) 2016 The Authors. This is an open access article under the terms of the Creative Commons Attribution-NonCommercialNoDerivs License, which permits use and distribution in any medium, provided the original work is properly cited, the use is non-commercial and no modifications or adaptations are made. 
shown that nurses should demonstrate a passion for their work and have the necessary proficiency and expertise to achieve the highest level of efficiency (2).

\subsection{Statement of the problem and study logic}

It could be argued that any person would provide better services if he or she were motivated and enthusiastic about the work. Despite the great significance of the professional satisfaction of nurses due to its considerable impact on them, their patients, their organizations, and the very profession of nursing (3), most previous studies have reported the satisfaction level to be low among nurses (4). The results from the study conducted by Lou et al. indicated that only half of the nurses in the study were moderately or highly satisfied with their work (5). Another study was conducted to compare the level of professional satisfaction among different groups of people in Korea, and it was found that only $41.5 \%$ of nurses were satisfied with their work, whereas the percentages for other experts working at hospitals, social workers, and middle school teachers were 50.1, 58.2, and $89 \%$, respectively. These statistics indicate that there is a lower level of satisfaction among nurses than other professionals (6). Various studies have been conducted regarding the extent of professional satisfaction among the nurses, and, sadly, all have indicated low degrees of satisfaction (7). Most nurses who work in Internal Medicine and Surgical Departments (54.4\%) demonstrated low levels of professional satisfaction (8). Overall, these studies suggested that the situation concerning nurses' professional satisfaction is unacceptable. It should be noted that a lack of sufficient concern towards professional satisfaction will result in serious consequences in the long run. It could give rise to rebellion, diminished feelings of responsibility, and eventually resignation from the job (9). Professional dissatisfaction among nurses could result in emotional detachment, depression, anger, evasion from work, and ineffectiveness (10). According to a qualitative study done in 2010 in India, the reasons nurses quit their jobs were determined to be professional exhaustion, stress at work, and lack of a friendly environment, all of which contributed to their diminished professional satisfaction. In addition, it was indicated that a strong relationship exists between professional dissatisfaction and quitting work (11). According to released statistics, the insufficient number of available nurses around the world is a tangible phenomenon. In Australia, for instance, there has been an annual demand for 13,500 nurses for the last decade. Furthermore, according to estimations, by 2010, Canada will need an additional 113,000 nurses, and, by 2020, the United States would incur a $20 \%$ shortage in the number of nurses (approximately 581,500 nurses) $(12,13)$. In Iran, one of the most problematic issues in nursing is the shortage of nursing staff. The shortage of nursing staff has different causes, including job dissatisfaction and organizational and sociocultural factors (14). In Iran, many studies have reported that nurses are not happy because of the shortage of nursing staff, high numbers of patients, the lack of independence and authority, the lack of appreciation and acknowledgment, low income, heavy workloads, low level of involvement in management, disagreements with physicians, managerial issues, and a lack of appropriate work conditions in hospitals (15). Approximately $45 \%$ of nurses in Iran regret having become nurses, whereas $43.9 \%$ of them feel disappointed and dissatisfied that they became nurses. The most challenging problem in nursing in Iran is the shortage of nurses working in hospitals because of their dissatisfaction and lack of motivation, and, unfortunately, most nurses in Iran would like to change their work (14).

\subsection{Objective}

Because satisfaction with nursing is related to improving the health system and patient satisfaction, this study was conducted to assess how the satisfaction of nurses with their work can be improved, their situation in hospitals can be improved, and also how patients' satisfaction could be increased (15). The objective of this research was to determine Iranian nurses' experiences of the concept of professional satisfaction.

\section{Material and Methods}

This was a qualitative study that was conducted with a targeted sampling of 10 nurses (4 men and 6 women), with a minimum of one year and a maximum of 25 years of work experience. All participants had earned a Bachelor's degree and cared for patients directly as staff members in general or intensive care units at public or private hospitals in Tehran. In this study, data were collected using semi-structured interviews. Before conducting the interviews, the objective of the study was explained to the participants, and their consent to participate in the study was obtained in writing. Furthermore, the interviews were recorded with the approval of the participants. All interviewees were ensured that their identities would not be disclosed in the reports and that they could have access to the results. Each interview took 50-70 min, and 18 interviews were conducted. The data were collected from the researcher's observations during the interviews. The interviews were conducted in a place where the participants felt comfortable, such as in the break room in the hospital where they worked. This study was initiated and completed in 2015. In addition to covering the general questions of the study, attempts were made to personalize each interview 
depending on its flow. Data collection continued until a state of information saturation was reached. The contents of the interviews were analyzed using the QCA method. The QCA is an analytical procedure that is utilized to provide a subjective interpretation of textual data contents (16). In this method, codes and categories are extracted from raw data directly and inductively through a systematic categorization process (17). Content analysis is much more than the extraction of objective contents out of textual data, i.e., key concepts and hidden patterns may be revealed from the content of the participant-generated data through this method (16). In the QCA, data collection and analysis are done simultaneously (17).

In this method, the researcher collects and analyzes data back and forth in order to collect new data to be able to provide answers to the research questions (16). Moreover, analytical units are selected from the texts of the interviews. An analytical unit is a part of text that can be analyzed to help achieve the research objectives. Initial codes were extracted from meaning units, which are important and reliable parts of the analytical units. Initial codes could contain either the exact content of the participant's interview or the abstract of the content. Based on their similarities and differences, the initial codes were reduced to sub-categories, which, in turn, were used to abstract categories and key concepts (17). In the first step of this study, the researchers listened to the interviews, and then they wrote the results of the interviews word for word. In the next step, the written text was analyzed, so initial codes were created. Then, based on similarities and differences, the initial codes were reduced to sub-categories, abstracts were prepared, and the key codes were identified. In order to achieve reliability in this research, the data were controlled by the participants and investigated by an investigation team. In addition to restoring the speech and experiences of the participants during the interviews by replaying them, the researcher gave them full typed texts of the first four interviews together with their initial codes to those with whom he or she had conducted the initial interviews for verified or revision. In addition, coding and initial categories with respect to content analysis were submitted to the researcher's supervisor, and verification was received on her/his part regarding the implementation, coding, and initial categories. In order to increase the reliability of the data, the researcher attempted to establish a deeper relationship with the participants and also allocated sufficient time for the interviews. The researcher also attempted to provide a friendly atmosphere in order to gain the participants' trust, so that more accurate data and information could be elicited. The participants were willing to participate in the interviews, and they express their feelings, experiences, and thoughts with no fear of censorship or pressure. Also, to increase the degree of reliability, the researcher attempted to avoid including his personal preferences in the study.

\section{Results}

From the qualitative analysis of the data collected from the interviewees, "fair conduct" was extracted as the turning point and basis upon which professional satisfaction of nurses could be achieved, which, in turn, consisted of three sub-categories, i.e., 1- expectation of fairness in social-professional settings, 2- expectation of fairness in receiving professional benefits, and 3- expectation of fairness in the area of professional interactions. All three of these subcategories are discussed below.

\subsection{Expectation of fairness in social-professional settings}

Many of the participants maintained that there was a gross distinction between what the society said and how people reacted, in that, even though nurses were academically educated, cared for patients, and dealt with their problems in a never-ending manner, they were not regarded by patients, their families, or even society as having an equal status to those engaged in other professions, including medicine. One of the nurses expressed her feelings by saying, "Nursing is a difficult job. You study for four years at university just like any other discipline, you get a bachelor degree, yet at the end, people regard nurses as a bunch of illiterates with no independence or literacy whatsoever, and who merely obey what doctors command them to do." Another nurse stated, "Society regards nurses as mere observers who tend their patients, but view doctors as "God's eyes", "God's appointed saviors on earth," and so on. Even those engaged in other fields such as accounting, engineering, etc. with equivalent bachelor degrees enjoy a better salary and are held in greater esteem than the people employed in nursing." Yet another participant stressed the significance of professional satisfaction in making nurses continue to do their jobs; "I become very upset when I see the respectful way by which people of other professions who have bachelor degrees just like we do, are referred to (e.g. "the engineer man/lady), or when I compare the level of respect shown to doctors with that shown to nurses. I realize that the difference is significant. People do not have high regards for the community of nurses; they view them as ill-humored or bad people. They are not even familiar with different ranks of nursing. In movies, nurses are shown wearing dressed with all kinds of colors running after doctors. Yet, in those same movies, doctors are displayed as distinguished people helping patients. You see, even in movies there is no justice!". 


\subsection{Expectation of fairness in receiving professional benefits}

Most of the participants stated that unfair practices at work with respect to financial matters had left them disappointed and lowered their professional satisfaction, in such a way that their attempts were directed towards quitting their job or finding a new one with better salary. Concerning this matter, one of the nurses stated, "In today's world my basic needs have to be fulfilled, and currently a nurse's salary is not in any sense proportionate to that earned by those working in other medical sectors." On lack of a financial fairness, another nurse maintained, "It might be true that a doctor's education is higher than that of a nurse, but a nurse devotes more of his/her time to patients, in return. They are awake all night long. This gross distinction in salaries is unbearable." Another participant touched on the distinction between nursing in Iran and overseas, "The thing that bothers the Iranian nurses the most is their awareness of all professional benefits that nurses working in other countries enjoy. In advanced countries, nursing has a high status, while this is not the case for Iran, and that is exactly the reason behind many dissatisfactions. A kind of financial injustice is at work." A male nurse expressed his discontent of nursing as follows, "With 35 years of age, I suffer from Diabetes due to the stress at work, which I try to handle with strict regiments and such. I am trying to change my job, since no matter how hard I work I end up having nothing. I have to hold two or three jobs to be able to buy a house. Yet, this is not the case for those engaging in other professions, with little or no difference than nursing from an academic point of view?" Another male nurse expressed his discontent of nursing as follows, "I know for a fact that, nurses in the Great Britain earn an equal amount of salary compared to surgeons, which is something to reflect upon. That how the monthly income of a nurse is equal to that of a surgeon is something that requires serious contemplation. Furthermore, they merely work one shift and tend two patients all night long, unlike in Iran, where two nurses tend 45 patients simultaneously." Another nurse with two years' experience said, "With rising inflation, doctors' salaries and fees increase day by day, whether officially or unofficially, and the authorities regard this as their inalienable right. However, nurses live off of a petty salary and then they complain about the few number of working nurses, and that why it is that they continually quit their job!"

\subsection{Expectation of fairness in the area of professional interactions}

Most of the participants viewed a number of factors as influencing the satisfaction they felt in doing their job, the most important of which was the viewpoint and attitude of hospital managers towards nurses. One of the participants in this study voiced her/his opinion on this matter as such, "The treatment received by nurses from hospital management is unfair. They do not show them the level of respect they deserve, yet always support doctors' rights." One of the nurses pointed to decision making by doctors or nurses as one of the factors causing professional dissatisfaction, "During all these years that I have worked as a nurse, I have seen with my own eyes that many decisions are made for us by those in the medical department. All regulations are in favor of physicians. They are just not fair!" Another participant stated, "Justice is not observed at Iranian hospitals. Nurses are always to blame." One of the nurses working in the Department of Psychiatry pointed to the following as one of the reasons behind his/her professional satisfaction, "I work in an environment with lots of hardships. Since, as you know, working with mentally-challenged patients drives one to exhaustion. Yet, despite all these hardships, our relationship with our managers is at a very high level. They act very reasonably, and this brings about satisfaction and makes us care for patients with greater motivation." The belief in establishing a kind of justice on the part of some of the participants was so strong that they viewed the existing difficulties in the nursing profession to be more bearable if some sense of justice was in place. The following statement could be brought to attention in this regard, "Despite the high level of physical and mental exhaustion that our work brings about, a fair treatment by managers and equality with respect to observing the rules would make the hardships of this job, including lack of sleep, intensity of work, low salary, etc. more bearable."

\section{Discussion}

As was discussed, one of the main components of professional satisfaction is fair conduct, which consists of three sub-categories, i.e., expectation of fairness in social-professional settings, expectation of fairness in receiving professional benefits, and expectation of fairness in the area of professional interactions. The subject of "fairness" is one of the few fundamental topics relevant to various spheres of science and philosophy, and it can be applied to any situation in terms of people's needs and expectations. The concept of fairness is integrated with moral and social values and within the sphere of morality, in particular social morality, supporting fairness and equity is of the most fundamental moral values. Organizational justice refers to an understanding on the part of staff about fair conduct. Researchers regard the establishment of justice as one of the most important factors affecting professional satisfaction (18). One of the long-term challenges of the nursing profession is its public image (19). There are various ups and downs to nursing due to the challenging nature of this profession from the initial education at university until retirement. Dropping out of university, quitting work, and professional dissatisfaction are important 
problems of the nursing profession. Although low salaries and benefits and professional exhaustion are among the factors causing discontent among nurses, according to conducted studies, lack of consideration towards the status and public image of the nursing profession is responsible for $70 \%$ of professional dissatisfaction (20). Generally, people form opinions or mental images of other individuals based on their look, way of clothing, reaction, communication, behavior and attitude (21). The "image" is the perception or assumption that the general public makes about an individual, profession, or organization. The people within those organizations use this image as a tool to communicate with people, and they, in turn, interact with those organizations based on the projected image, whether positive or negative (20). The social status of a profession and the society's perspective towards it are of effective motivational factors influencing the extent of professional satisfaction, which, in turn, leaves an impact on the attitude shown by individuals in fulfilling their professional functions. These statuses include placing a high value on a profession and its required proficiencies and the value and status of a profession in a particular society. Whenever the status is damaged on a societal scale, the status of the profession is also diminished (22). In nursing, one of the most important concerns with regards to professional status is lack of a high value and social status within society. With regards to the importance of this issue, Stevens stated that public opinion acts very strongly in determining the social structure and norms of a society (23). A positive public image will leave a considerable effect on gaining social and situational support. As was understood from the findings of this study, most nurses in this research regarded professional satisfaction as manifested through expectation of fairness in social-professional settings. Regarding the second important finding of this study, i.e., the expectation of fairness in receiving professional benefits, the participants stated that unequal salaries among the personnel of the medical department and a gross distinction between the payments to the medical staff have been sources of disappointment and dissatisfaction. Markovsky was among the first theoreticians to recognize the significance of the issue of salary satisfaction in observing fairness (24). Therefore, the findings of this study, that is, feeling a sense of fairness in receiving professional benefits has an intermediary role in bringing professional satisfaction, is in line with Markovsky's theory. Furthermore, expectation of fairness in receiving professional benefits gives the indication that, if individuals deem a condition to be unfair, they will have an emotional response to it (25). Yet another important finding of this study was the expectation of fairness in professional interactions. The participants of this study stated that the treatment they receive from managers is unfair and disrespectful compared to other health teams. Maxham et al. defined interactional justice as the feeling experienced by employees when interacting with their supervisor and state; cooperation with supervisors and other members of the work team and respectful behavior, and providing the required information would result in a high satisfaction level among employees (25). Kim et al. maintained that interactional fairness, fair treatment by managers towards employees, and instituting behavioral justice significantly affect professional satisfaction (26). Regarding the issue of "fairness," the results of the present study were in line with those obtained by Lou et al. (21), in which it was demonstrated that British nurses were more displeased compared to Australian nurses. The British nurses felt that their professional statuses were lower, their relationships with hospital managers were weaker, and their work conditions were less favorable than those of Australian nurses. The British nurses reported a low level of respect from hospital managers. The results of this study confirm the point that the existence of a relative social status to profession, and of justice within the work environment, and also respectful treatment towards nurses by management. Generally speaking, fair conduct is an integral part of professional satisfaction in the nursing profession, which could encourage nurses to employ the related measures and interventions with a higher degree of motivation (18). Furthermore, a review of the previous studies indicated that management and administrative experiences, which refer to organizational structures, such as (de)centralization and fair and transparent organizational policies and procedures are among the factors affecting professional satisfaction. Researchers have found out that decentralization and all kinds of cooperative management models are more to nurses' liking, and that they resent being looked at with indifference, and this leads to a lower professional satisfaction level in their eyes (12). The study conducted by Farsi et al. indicated that the low public image of nursing in the Iranian society has caused nurses to feel unappreciated and disrespected (16). As was demonstrated in other studies conducted in Iran, the motivation level of Iranian nurses in fulfilling their professional tasks, which to a large degree is dependent upon the public image, is not acceptable (20).

\section{Conclusions}

In general, since professional satisfaction is a single concept that cannot be deconstructed, it is possible to be defined by individuals in vague manners. Therefore, professional satisfaction can be viewed as a general feeling, or as the attitude taken by an individual with respect to part of her or his job. Overall, it is possible to improve the professional satisfaction of nurses through emphasizing the (in)visible aspects of professional satisfaction, such as fair conduct, removing tension-generating factors, improving the attitude of society towards the nursing profession, 
establishing justice among all hospital staff, improving communication, organizing the nursing profession, and enhancing the payment system and making it fair.

\section{Acknowledgments:}

This work was part of a Ph.D. dissertation, and it was supported financially by the Tehran University of Medical Sciences (grant number 11542).

\section{Conflict of Interest:}

There is no conflict of interest to be declared.

\section{Authors' contributions:}

All authors contributed to this project and article equally. All authors read and approved the final manuscript.

\section{References:}

1) Rajabipoor MA, Dehghani M. The relationship between islamic work ethic and organizational commitment and job satisfaction of nurses. Journal of Bioethics. 2013; 2(6): 43.

2) Ahmad AR, Adi MNM, Noor HM, Rahman AGA, Yushuang T. The Influence of Leadership Style on Job Satisfaction among Nurses. Asian Social Science. 2013; 9(9): 172. doi: 10.5539/ass.v9n9p172.

3) Murrells T, Clinton M, Robinson S. Job satisfaction in nursing: validation of a new instrument for the UK. J Nurs Manag. 2005; 13(4): 296. doi: 10.1111/j.1365-2934.2005.00531.x.

4) Aiken LH, Clarke SP, Sloane DM, Sochalski JA, Busse R, Clarke H, et al. Nurses' reports on hospital care in five countries. Health Aff. 2001; 20(3): 43-53. doi: 10.1377/hlthaff.20.3.43.

5) $\mathrm{Lu} \mathrm{H}$, While AE, Barriball KL. Job satisfaction and its related factors: A questionnaire survey of hospital nurses in Mainland China. Int J Nurs Stud. 2007; 44(4): 574-88. doi: 10.1016/j.ijnurstu.2006.07.007.

6) Park M, Lee J, Cho S. Newly graduated nurses' job satisfaction: comparison with allied hospital professionals, social workers, and elementary school teachers. Asian Nurs Res. 2012; 6(3): 85. doi: 10.1016/j.anr.2012.06.001.

7) Kwak C, Chung B, Xu Y, Eun-Jung C. Relationship of job satisfaction with perceived organizational support and quality of care among South Korean nurses: a questionnaire survey. Int J Nurs Stud. 2010; 47(10): 1292. doi: 10.1016/j.ijnurstu.2010.02.014.

8) Kamal S, Al-Dhshan M, Abu-Salameh K, Abuadas F, Hassan M. The effect of nurses' perceived job related stressors on job satisfaction in Taif governmental hospitals in Kingdom of Saudi Arabia. Journal of American Science. 2012; 8(3): 119-25.

9) Top M, Tarcan M, Tekingündüz S, Hikmet N. An analysis of relationships among transformational leadership, job satisfaction, organizational commitment and organizational trust in two Turkish hospitals. Int J Health Plann Mgmt. 2013; 28(3): e217. doi: 10.1002/hpm.2154.

10) Tajvar M, Arab M, Khodabakhsh-Nejad V. Job satisfaction in Tehran Children Medical Center 2003. Health Management. 2006; 9(23): 25-30.

11) Mohsenpur L, Navipur H, Ahmadi F. The study effect cooperative management on based on the quality circles of job satisfaction of nurses from perspective Herzberg. J Army Univ Med Sci. 2005; 3(4): 694-8.

12) Feather RA. Staff nurse perceptions of nurse manager behaviors that influence job satisfaction. Indiana University; 2011.

13) Hayes B, Bonner A, Pryor J. Factors contributing to nurse job satisfaction in the acute hospital setting: a review of recent literature. J Nurs Manag. 2010; 18(7): 804-14. doi: 10.1111/j.1365-2834.2010.01131.x.

14) Zarea K, Negarandeh R, Dehghan - Nayeri N, Rezaei - Adaryani M. Nursing staff shortages and job satisfaction in Iran: Issues and challenges. Nursing \& health sciences. 2009; 11(3): 326-31. doi: 10.1111/j.1442-2018.2009.00466.x.

15) Farsi Z, Dehghan-Nayeri N, Negarandeh R, Broomand S. Nursing profession in Iran: an overview of opportunities and challenges. Jpn J Nurs Sci. 2010; 7(1): 9. doi: 10.1111/j.1742-7924.2010.00137.x.

16) Hsieh H-F, Shannon SE. Three approaches to qualitative content analysis. Qual Health Res. 2005; 15(9): 1277-88.doi: 10.1177/1049732305276687.

17) Wildemuth BM. Applications of social research methods to questions in information and library science. Journal. 2009, Available from: http://www.ils.unc.edu/ yanz/Content\%20analysis.pdf

18) Rezaei-Adaryani M, Salsali M, Mohammadi E. Nursing image: an evolutionary concept analysis. Contemp Nurse. 2012; 43(1): 81. doi: 10.5172/conu.2012.43.1.81.

19) Hall C. Professional image of a nurse. Nurses Association of Botswana; 2012. 
20) Ravari A, Bazargan M, Vanaki Z, Mirzaei T. Job satisfaction among Iranian hospital-based practicing nurses: examining the influence of self-expectation, social interaction and organisational situations. J Nurs Manag. 2012; 20(4): 522. doi: 10.1111/j.1365-2834.2010.01188.x.

21) McHugh M, Kutney-Lee A, Cimiotti J, Sloane D, Aiken L. Nurses' widespread job dissatisfaction, burnout, and frustration with health benefits signal problems for patient care. Health Aff (Project Hope). 2011; 30(2): 202. doi: 10.1377/hlthaff.2010.0100.

22) Abu Elanain HM. Testing the direct and indirect relationship between organizational justice and work outcomes in a non-Western context of the UAE. Journal of Mgmt Development. 2010; 29(1): 5-27. doi: $10.1108 / 02621711011009045$.

23) Maxham III JG, Netemeyer RG, Lichtenstein DR. The Retail Value Chain: Linking Employee Perceptions to Employee Performance, Customer Evaluations, and Store Performance. Marketing Science 2008;27(2). DOI: $10.1287 / \mathrm{mksc} .1070 .0282$

24) Kim J-Y, Moon J, Han D, Tikoo S. Perceptions of justice and employee willingness to engage in customeroriented behavior. Journal of services marketing 2004;18(4):267-75. DOI: 10.1108/08876040410542263

25) $\mathrm{Lu} \mathrm{H}$, While A, Barriball K. Job satisfaction among nurses: a literature review. Int J Nurs Stud 2005;42(2):211. DOI: 10.5953/jmjh.2013.20.3.235

26) Sengin K. Work-related attributes of $\mathrm{RN}$ job satisfaction in acute care hospitals. J Nurs Adm 2003;33(6):317. DOI: 10.1097/00005110-200306000-00002 